\title{
REVISTA EM QUADRINHOS COMO RECURSO METODOLÓGICO LÚDICO NO ENSINO DE BIOLOGIA: UMA EXPERIÊNCIA PRÁTICA NA EDUCAÇÃO BÁSICA
}

\author{
JOURNALS IN BOOKS AS A METHODOLOGICAL RESOURCE LUDIC IN TEACHING BIOLOGY: \\ A PRACTICAL EXPERIENCE IN BASIC EDUCATION
}

LAS REVISTAS EN LIBROS COMO RECURSO METODOLÓGICO LÚDICO EN LA ENSEÑANZA DE LA BIOLOGÍA: UNA EXPERIENCIA PRÁCTICA EN EDUCACIÓN BÁSICA

\section{Natanael Charles da Silva (iD) 9}

Doutorando em Ensino (UFRN)

Professor de biologia pelo Instituto Federal do Pará - Campus

Abaetetuba

natanaelcharles@gmail.com

\section{Fernanda Costa de Freitas}

\section{iD 9}

Graduanda do Curso de

Licenciatura em Ciências

Biológicas pelo IFPA

nandinhafreitas676@gmail.com

\section{Patrícia Nazaré Alcântara de Carvalho \\ iD 9}

Graduanda do Curso de

Licenciatura em Ciências

Biológicas pelo IFPA

patyhistory@gmail.com

\begin{abstract}
Resumo
Um dos grandes desafios para os professores de biologia ainda é a falta de materiais didáticos que possam intermediar e melhorar a compreensão dos alunos sobre os conteúdos ministrados. Assim, o trabalho objetivou produzir e utilizar revista em quadrinhos como ferramenta metodológica para o ensino e aprendizagem dos transgênicos. Para tanto, foi utilizado o aplicativo Cômica para criação dos personagens e o programa Microsoft Word 2013 para formatação. O recurso foi aplicado na escola Pública Estadual Leônidas Monte no Município de Abaetetuba - Pará durante a monitoria do PIBID. Com a aplicação de um questionário de satisfação, obtivemos que $67 \%$ dos alunos não tinham conhecimentos prévios sobre alimentos transgênicos, $75 \%$ afirmaram que a revista facilitou muito o entendimento sobre o assunto, $67 \%$ querem que essa metodologia seja aplicada em outras aulas, $75 \%$ consideraram a revista dinâmica, divertida e estimulante no aprendizado do conteúdo e $87 \%$ gostaram da revista de modo geral. Em entrevista, a professora da turma considerou que por ser um material com ilustrações, linguagem simples e divertida, a revista facilitou a assimilação do conteúdo. Consideramos os resultados satisfatórios, havendo receptividade positiva da metodologia tanto pelos alunos quanto pela professora da turma de aplicação. Palavras-chave: Revista em Quadrinhos. Material Didático. Ludicidade. Ensino de Biologia.
\end{abstract}

Recebido em: 31 de janeiro de 2021. Aprovado em: 22 de março de 2021.

Como citar esse artigo (ABNT):

SILVA, Natanael Charles da; FREITAS, Fernanda Costa de; ALCÂNTARA, Patrícia Nazaré. Revista em quadrinhos como recurso metodológico lúdico no ensino de biologia: uma experiência prática na educação básica. Revista Prática $\begin{array}{llllll}\text { Docente, } & \text { v. } & 6, & \text { n. } & 1, & \text { e014, }\end{array}$ http://doi.org/10.23926/RPD.2021.v6.n1.e014.id1007 


\section{Abstract}

One of the great challenges for biology teachers is still the lack of teaching materials that can mediate and improve students' understanding of the contents taught. Thus, the work aimed to produce and use comic books as a methodological tool for the teaching and learning of transgenics. For that, the application Comics was used to create the characters and the Microsoft Word 2013 program for formatting. The resource was applied at Leônidas Monte State Public School in Abaetetuba - Pará during the monitoring of PIBID. With the application of a satisfaction questionnaire, we obtained that $67 \%$ of the students had no previous knowledge about transgenic foods, $75 \%$ stated that the magazine made it easier to understand the subject, $67 \%$ want this methodology to be applied in other classes, $75 \%$ found the magazine dynamic, fun and stimulating in learning the content and $87 \%$ liked the magazine in general. In an interview, the class teacher considered that because it was a material with illustrations, simple and fun language, the magazine facilitated the assimilation of the content. We consider the results satisfactory, with positive receptivity of the methodology by both the students and the teacher of the application class.

Keywords: Comic Book Magazine. Courseware. Playfulness. Biology teaching.

\section{Resumen}

Uno de los grandes retos para los profesores de biología sigue siendo la falta de materiales didácticos que puedan mediar la comprensión de los contenidos por los estudiantes. Así, el trabajo tuvo como objetivo producir y utilizar los cómics como herramienta metodológica para la enseñanza y aprendizaje de los transgénicos. Para eso, se utilizó la aplicación Comics para crear los personajes y el programa Microsoft Word 2013 para formatear. El recurso se aplicó en la Escuela Pública Estatal Leônidas Monte en Abaetetuba - Pará durante el monitoreo del PIBID. Con lo cuestionario de satisfacción, obtuvimos que $67 \%$ de los estudiantes no tenían conocimientos previos sobre alimentos transgénicos, $75 \%$ manifestó que la revista facilitó la comprensión del tema, 67\% quiere que esta metodología se aplique en otras clases, $75 \%$ le pareció que la revista era dinámica, divertida y estimulante para aprender el contenido y $87 \%$ le gustó la revista en general. En entrevista, la profesora de la clase consideró por tratarse de un material con ilustraciones, lenguaje sencillo y divertido, la revista facilitó la asimilación del contenido. Consideramos satisfactorios los resultados, con receptividad positiva de la metodología tanto por parte de los alumnos como del docente de la clase de aplicación.

Palabras Clave: Revista de cómics. Material didáctico. Alegría. Enseñanza de la biología. 


\section{INTRODUÇÃ̃o}

Para Freire (1996) ensinar não é transferir conhecimento, mas criar as possibilidades para a sua própria produção ou a sua construção. Com isso, a procura por metodologias de ensino através da ludicidade, por exemplo, tem se tornado uma alternativa muito viável para aqueles que desejam fugir um pouco do ensino tradicional e adotar um ambiente mais dinâmico para as aulas de Ciências e Biologia.

Segundo Almeida (2003) por meio do lúdico o professor consegue desenvolver atividades divertidas e que principalmente instrua o aluno a distinguir valores éticos e morais, possibilitando a formação de um cidadão consciente dos seus deveres, além de ter a possibilidade de criar situações onde a relação professor-aluno seja de troca de experiências e aprendizagem.

Como professor crítico, sou um "aventureiro" responsável, predisposto à mudança, à aceitação diferente (FREIRE, 1996), com isso, entende-se que os alunos podem adquirir uma aprendizagem significativa se as aulas apresentarem certo diferencial, possibilitando o aluno esquecer que está estudando, tornando a aprendizagem um processo natural.

Desde a década de 1960, as Histórias em Quadrinhos (HQs) têm se propagado no âmbito do ensino formal, a princípio sendo utilizadas em aulas de Língua Estrangeira e Língua Portuguesa e, posteriormente, em outras áreas, ganhando destaque como ferramenta pedagógica ao tratar de diversos assuntos como Matemática, Comunicação e Expressão, Ciências Físicas e Biológicas, História, Moral e Civismo e Religião (SILVA, 1985).

Para Linsingen (2007) os quadrinhos se constituem em uma forma de arte sequencial que informa e educa, sendo estruturada pela imagem e pela escrita. Ao mesmo tempo, possuem uma linguagem verbal e não verbal, objetiva e popular vinculada ao cotidiano, onde a ação está presente, perpassando a ideia de movimento, de 'língua falada' e onde se nota vários fatos/acontecimentos ao mesmo tempo, de maneira simples e divertida.

As HQs auxiliam na veiculação de temas específicos a um maior número de pessoas. Isto porque, sua linguagem caracteriza-se por combinar a imagem com o texto escrito, articulando assim temas do cotidiano. É uma literatura marcada pelas ideias da sociedade da época, para atingir um determinado objetivo. Isso sem mencionar que seus textos revelam as mais diversas intenções, como, informar, convencer, seduzir, divertir, sugerir estados de ânimo, entre outras (CIRNE, 2000). 
O avanço da ciência nos últimos anos proporcionou a descoberta de novas tecnologias, como a biotecnologia, cujas técnicas são essenciais para o progresso da humanidade (RIBEIRO; MARIN, 2012). Nesse contexto, os Organismos Geneticamente Modificados (OGMs), podem ser considerados um avanço científico e uma certeza de lucro para os grandes centros de biotecnologia e para os produtores rurais.

Dentro deste contexto, o termo transgênico foi usado pela primeira vez em 1983, na Universidade da Pensilvânia, quando dois cientistas inseriram genes humanos de hormônios de crescimento em embriões de ratos, produzindo os chamados "super ratos". A palavra transgênico é utilizada para designar um ser vivo que foi modificado geneticamente, recebendo um gene com uma sequência gênica de um ser vivo de espécie diferente (ALVES, 2004).

Este tema tão polêmico atualmente é discutido no ambiente escolar dentro do ensino de biologia, onde, tanto os cientistas como os educadores acham importante que a sociedade obtenha conhecimento dos processos da Ciência e Tecnologia. Deste modo, o aluno ao sair do ensino médio deve levar consigo os conhecimentos básicos da área, possibilitando-o analisar processos de investigação científica e suas implicações sociais. Com este conhecimento o discente terá a possibilidade de avaliar as vantagens e desvantagens dos avanços das técnicas da biotecnologia e biologia molecular, por exemplo.

Partindo desta vertente se faz necessário a utilização de metodologias que despertem o interesse e estimule o processo de ensino e aprendizagem nos alunos. A escolha da revista em quadrinho como recurso metodológico lúdico, justifica-se também pelo fato de concordarmos com Almeida et al. (2016) quando afirmam que através das atividades lúdicas o educador pode criar inúmeras condições para o educando desenvolver habilidades, pois é um método que possibilita a aplicação de aulas com mais práticas, nessas ocasiões os alunos interagem mais e criam o senso investigativo. Desta forma, o tema alimentos transgênicos dentro do ensino de biologia foi escolhido pelo nível de curiosidade e divergência de ideias e conceitos relacionados ao mesmo, bem como, por seguirmos a matriz de referência da Base Nacional Comum Curricular para o Ensino Médio.

Pode-se dizer que para as Histórias em Quadrinhos não há um limite de uso em sala de aula. Elas podem ser usadas para introduzir um tema, aprofundar um conceito, para gerar discussões ou para encerrar um determinado conteúdo, atuando de forma lúdica, pois as HQs unem aprendizagem e ludicidade (MARTINS, 2012). 
Com isso, a metodologia foi aplicada em turmas de alunos do terceiro ano do ensino médio participantes do Programa Institucional de Bolsas de Iniciação à Docência (PIBID), que é uma ação da Política Nacional de Formação de Professores do Ministério da Educação (MEC) que visa proporcionar aos discentes na primeira metade do curso de licenciatura uma aproximação prática com o cotidiano das escolas públicas de educação básica e com o contexto em que elas estão inseridas (BRASIL, 2020). Dando possibilidade de vivência no ambiente escolar, além de proporcionar desenvolvimento pessoal direcionado à docência.

Assim, o presente artigo objetivou produzir e utilizar revista em quadrinhos como ferramenta metodológica lúdica para o ensino e aprendizagem dos transgênicos, além de investigar de que forma a revista em quadrinhos pode facilitar o processo de ensino e aprendizagem dos discentes.

\section{MATERial E MÉtodo}

\subsection{LÓCUS E CARACTERIZAÇÃO DA PESQUISA}

A pesquisa caracteriza-se como quantitativa e qualitativa, realizando aplicação de um questionário com perguntas objetivas após a aplicação da metodologia de ensino, bem como, observações durante a realização da mesma e uma entrevista semiestruturada com a professora supervisora do programa na escola.

A produção da revista foi realizada durante o período das férias de julho do ano 20219 no Instituto Federal do Pará (IFPA) Campus Abaetetuba, seguida de sua aplicação no semestre seguinte (agosto de 2019) na Escola Estadual de Educação Básica Leônidas Monte situada no município de Abaetetuba - Pará durante a execução do PIBID. A aplicação da metodologia proposta foi acompanhada pela professora de biologia responsável pelas turmas na referida escola e supervisora local do programa PIBID.

\subsection{USO DA REVISTA EM QUADRINHOS}

Depois de pronta a revista foi aplicada como recurso metodológico à discentes do período vespertino na escola Leônidas Monte no município de Abaetetuba-PA. A escola recebe alunos do PIBID ao qual fazemos parte, foi realizada uma aula sobre Biotecnologia onde abordamos conceitos e aplicações de suas técnicas, em especial os transgênicos.

A revista foi utilizada em duas aulas seguidas de 50 minutos cada, onde foram intercaladas informações desta com informações do livro didático sobre o assunto, além de exposição de figuras e textos através de projeção de slides utilizando um data show. No final 
da última aula, os alunos tiveram um tempo para realizar a leitura completa da revista que cada um já tinha em mãos.

Após a execução da aula e uso da revista, foi aplicado um questionário aos alunos, de carácter quantitativo com a finalidade de investigar a aceitabilidade dos mesmos sobre a metodologia de ensino utilizada. Além disso, foi realizada uma entrevista com a professora de biologia responsável pela turma de aplicação. Ambos os envolvidos preencheram e assinaram um termo de livre esclarecido autorizando participação na pesquisa.

\section{ReSUltados E DISCUSSÃO}

\subsection{ProduÇÃo E aPliCAÇão da REVISTA}

Inicialmente foi realizado um levantamento bibliográfico referente ao assunto alimentos transgênicos através de artigos, revistas, sites e vídeos. Posteriormente de forma bem cuidadosa iniciou-se a formação das falas dos personagens da revista. Em seguida fomos à procura de um aplicativo que nos possibilitasse a criação dos personagens em quadrinhos e outro onde pudéssemos fazer a edição da mesma.

O aplicativo utilizado para a criação dos personagens do quadrinho foi o Cômica (Figura 1), aplicativo de edição de fotos de aparelho celular disponível no Play Store. O cômica consiste em um aplicativo que nos dar a possibilidade de poder transformar fotos em quadrinhos ou desenhos animados. Ao selecionar qualquer foto da galeria do celular (ou tirar uma nova), a foto é direcionada para os filtros onde temos várias opções de edição para transformá-la em um desenho animado ou em quadrinhos. Feito isso, o próximo passo foi adicionar quadrinhos como balões de fala e balões de pensamento. 
Figura 1 - Aplicativo Cômica utilizado na produção da revista

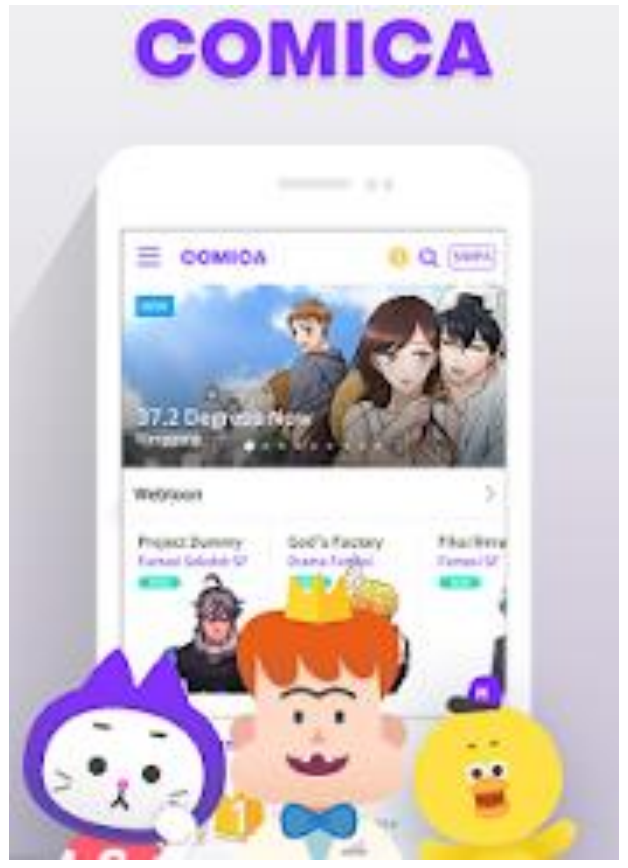

Fonte:

https://play.google.com/store/apps/details?id=com.comica.comics.google\&referrer=utm_source\%3Dhomepackb uzz\%26utm_medium\%3Dhomepack\%26utm_term\%3D1726699 (2020).

Os personagens dos quadrinhos foram criados a partir de fotos dos próprios monitores do PIBID atuantes na escola, que assinaram um termo de consentimento e livre esclarecido de participação na produção e divulgação da RQ. Tentando com isso, estabelecer ainda mais aproximação entre o conteúdo abordado pela revista com o cotidiano dos alunos.

Para edição (Figura 2) utilizamos o programa de computador Microsoft Word 2013 programa de criação de textos e documentos com diversas ferramentas. O Microsoft Word 2013 é um programa de processamento de texto, que é projetado para ajudar a criar documentos com qualidade profissional. Podendo ajudar a organizar e escrever os documentos de forma mais eficiente.

Figura 2 - Edição e formatação da Revista em Quadrinhos

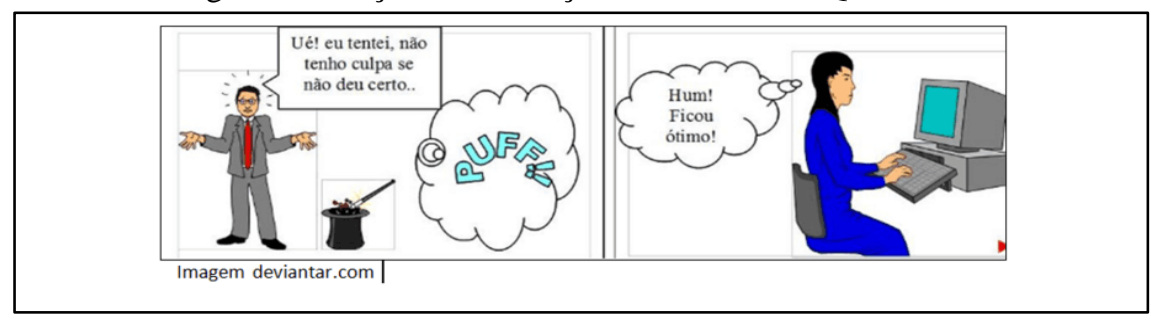

Fonte: https://novaescola.org.br/conteudo/12237/como-usar-mais-e-melhor-o-word-em-sala-de-aula (2020).

Com o auxílio de um aparelho celular, tiramos fotos no Hall do IFPA em diversos ângulos e diferentes movimentos com os lábios, além de gestos que pudessem transmitir 
emoções e movimentos de fala. Após as fotos já estarem prontas, seguimos para a segunda etapa que foi a edição destas no aparelho celular com o aplicativo cômica já instalado.

Com isso, as fotos foram enviadas para o notebook onde foram editadas no Microsoft Word 2013 utilizando as ferramentas de formas, como: balões e quadros. Em seguida foi criada uma caixa de texto para serem escritas as falas dos personagens. Após a edição da revista um professor de língua portuguesa realizou uma revisão ortográfica. Depois da correção, a revista foi salva em PDF e impressa na própria escola (uma via para cada aluno) para ser usada em sala.

\subsection{ANÁLISE DO QUESTIONÁRIO}

O questionário aplicado foi composto por questões objetivas onde as respostas possuem um padrão de sim totalmente, quando o indivíduo concorda totalmente com a afirmativa da pergunta, não totalmente, quando o indivíduo não concorda totalmente com a afirmativa da pergunta, sim parcialmente, quando o indivíduo concordo com partes da afirmativa da pergunta ou está em dúvida sobre sua resposta, e não parcialmente, quando o indivíduo mais discorda do que concorda com a afirmativa da pergunta porém não discorda totalmente desta.

Quando perguntados se já possuíam conhecimento sobre os alimentos transgênicos antes do contato com a revista, $67 \%$ dos alunos entrevistados responderam não totalmente (figura 3), indicando assim um grande quantitativo de alunos que nunca ouviram falar sobre o assunto. É possível inferir com isso, que o fato de um assunto estar na pauta de discussões cotidianas, motivadas por preocupações de cunho político, econômico, social, ecológico, não garante ao sujeito o entendimento sobre ele (PEDRANCINI et al., 2008).

Isso fortalece a ideia de que, o maior meio de conhecimento de novas técnicas científicas é adquirido na escola e em especial nas aulas de Biologia. Este assunto é de suma importância e deve ser discutido com frequência em sala de aula. Pedrancini et al. (2008) afirmam que é interessante ressaltar que as manifestações dos alunos em relação ao que sabiam sobre o assunto revelam que há contribuição da escola na aquisição desse conhecimento. 
Figura 3 - Gráfico representando respostas da pergunta 1: Antes da ministração da aula de biotecnologia e apresentação da revista você já tinha conhecimento sobre os alimentos transgênicos?

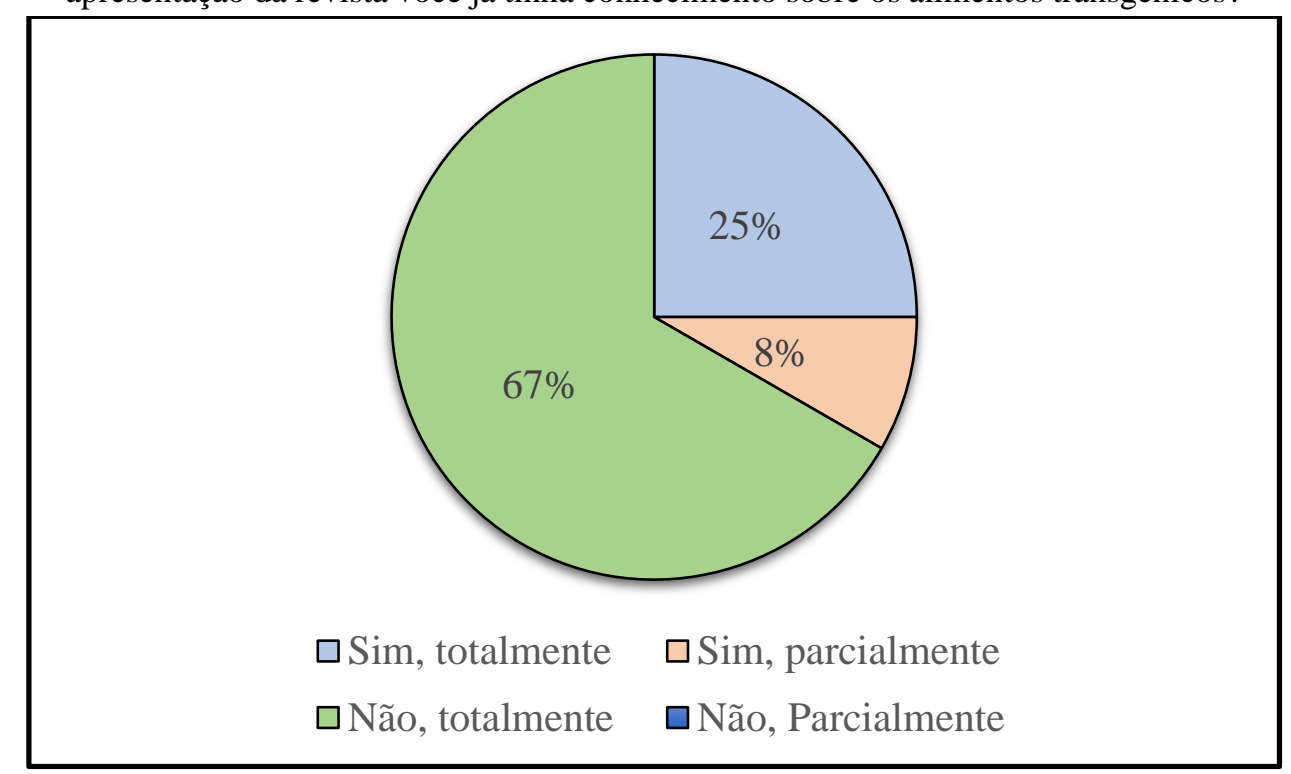

Fonte: Produzido pelos autores (2020).

Dentre os entrevistados, houve um percentual de 75\% (figura 4) que afirmaram a revista ter facilitado muito o entendimento sobre os alimentos transgênicos, $17 \%$ facilitou parcialmente o seu entendimento e outros $8 \%$ dizem que não parcialmente.

Figura 4 - Gráfico representando respostas da pergunta 2: A revista facilitou seu entendimento do que seria alimentos transgênicos?

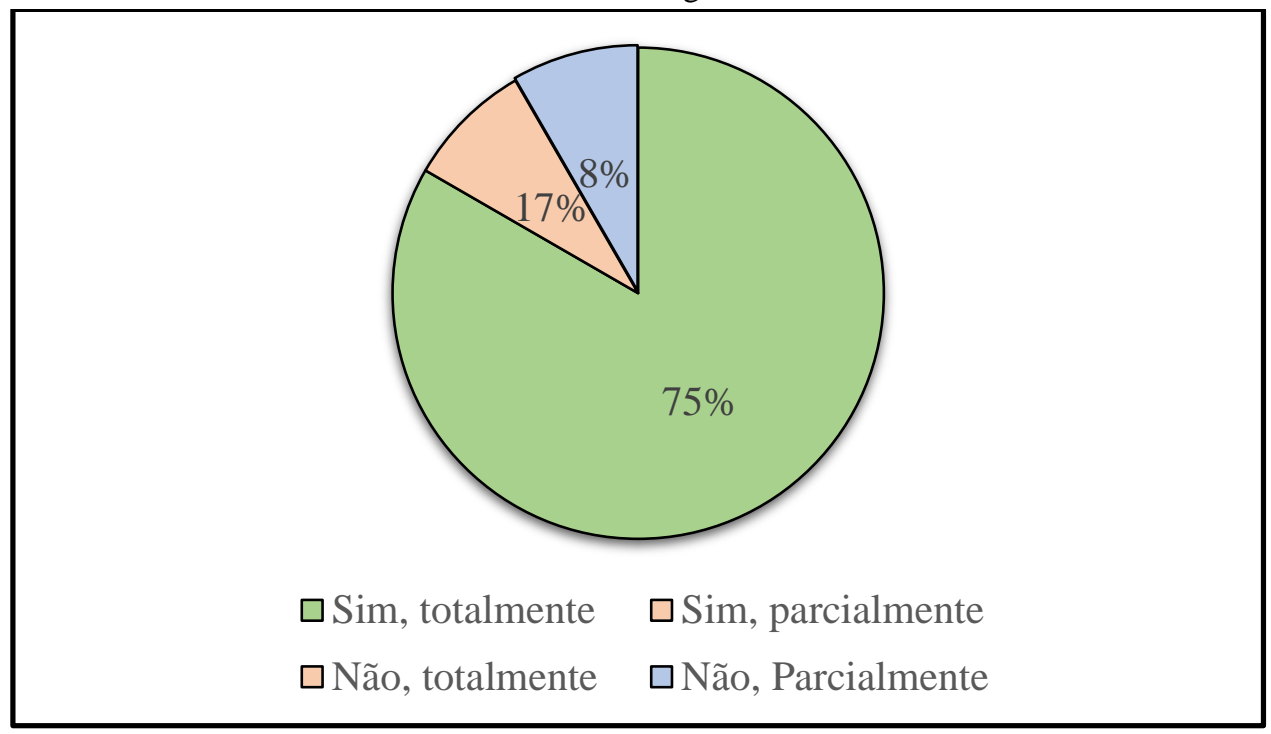

Fonte: Produzido pelos autores (2020).

Por mais que a revista não tenha atingido todos os alunos é notável que a utilização de um material diferenciado em sala de aula ajuda muito na assimilação do conteúdo. Concordando assim com Cardoso et al. (2017) quando afirma que o interesse dos alunos pelas aulas é difícil de ser mantido por estarem cansados da obrigatoriedade de frequência às escolas, com isso, as 
aulas lúdicas servirão para entrelaçar a teoria com a prática de forma que os estudantes fiquem atentos onde o conteúdo será absorvido de forma significativa.

Os indicadores podem mostrar ainda que recursos metodológicos lúdicos que fogem totalmente do modo tradicional de ensino podem ser utilizados como forma de levar informações sérias e científicas sobre assuntos diversos. Práticas científicas são complexas e exigem uma atenção redobrada, com isso, a revista apresentou-se de forma positiva para ajudar o aluno a entender o conteúdo de modo dinâmica e divertida.

Cabrera e Salvi (2006) afirmam que o lúdico cria descontração, favorece o envolvimento e o fluxo, condições essas necessárias para estabelecer o clima para a aprendizagem na busca de resultados positivos.

Quando perguntados sobre a intenção de ser utilizado a metodologia da Revista em Quadrinhos em outras aulas (figura 5), obtivemos 67\% dos alunos entrevistados afirmando que querem que essa metodologia seja aplicada em outras aulas, $16 \%$ aceitam parcialmente e $17 \%$ não discordam totalmente da metodologia, ou seja, aceitam em meio termo.

Figura 5 - Gráfico representando respostas da pergunta 3: Você gostaria que as outras aulas fossem usadas revistas como estas para melhor assimilação de conteúdo?

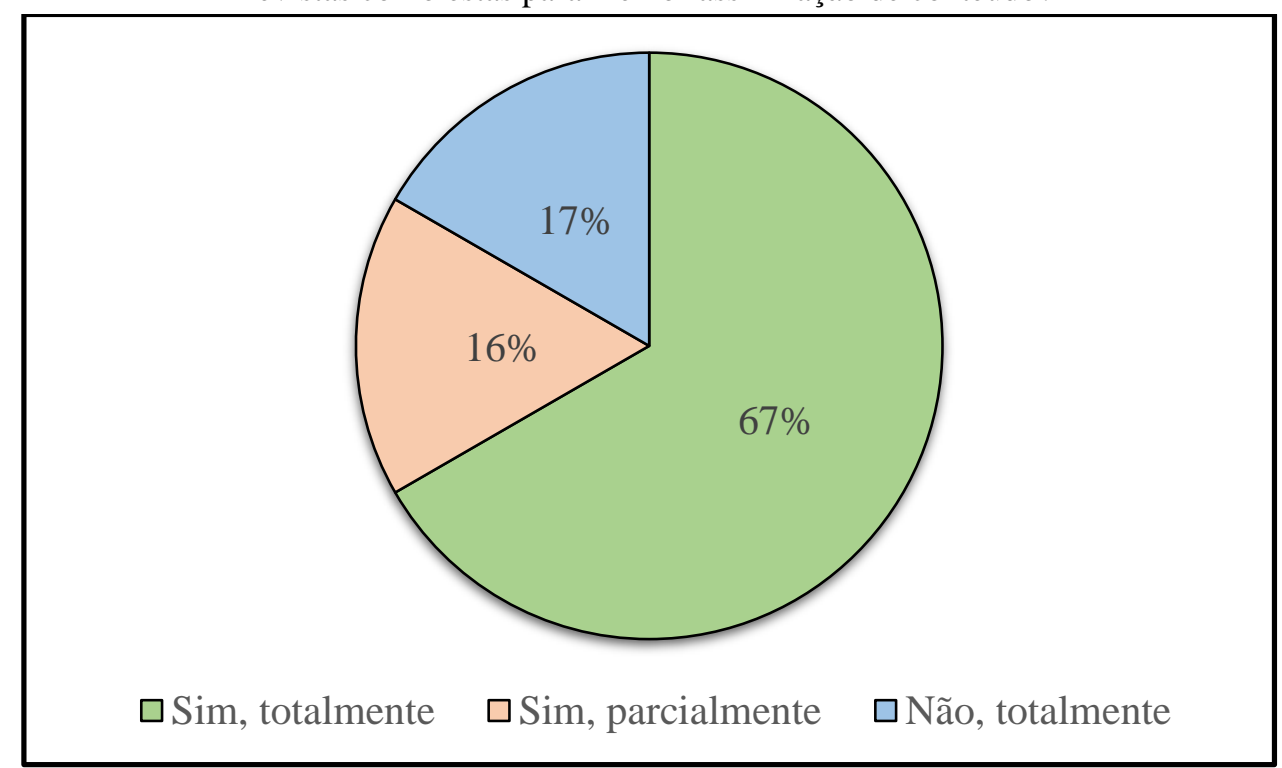

Fonte: Produzido pelos autores (2020).

Mesmo com um percentual alto de aceitação, percebemos que a revista não estimulou a todos os alunos a desejarem obter novas informações através da mesma para uma melhor assimilação de conteúdo, o que gerou preocupação, uma vez que, o importante não seria apenas fazer com que eles aprendessem, mas também gerar neles o interesse para que sozinhos pudessem buscar novas informações e assim se tornassem ativos no processo de aprendizagem. 
Nesse sentido, Almeida et al. (2016) corroboram afirmando que a apresentação de novas informações, incluindo o uso de atividades lúdicas, pode proporcionar aos alunos uma aprendizagem significativa. Acreditamos também que muitos sentem-se confortáveis e acomodados com o modo de ensino tradicional, apresentando certa resistência a determinadas mudanças e apresentação de novos recursos metodológicos.

Sobre a dinamicidade da metodologia utilizada (figura 6), alcançamos o resultado de 75\% dos alunos consideraram a revista dinâmica, divertida e estimulante no aprendizado do conteúdo, $17 \%$ julgaram parcialmente positiva e $8 \%$ não acharam a revista estimulante, dinâmica e divertida. Pode-se perceber que a maioria dos alunos aceita de forma positiva a metodologia exatamente por sair do modo tradicional de uso do livro didático em de sala de aula, e por ser uma novidade que chamou bastante a atenção deles.

Figura 6 - Gráfico representando respostas da pergunta 4: A revista foi algo dinâmico, divertido e estimulante para o seu aprendizado?

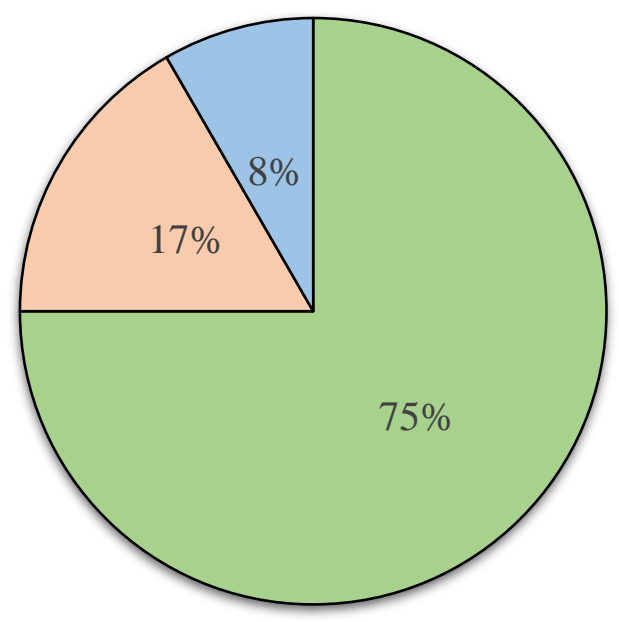

$\square$ Sim, totalmente $\quad \square$ Sim, parcialmente $\quad \square$ Não, totalmente

Fonte: Produzido pelos autores (2020).

Para Mendonça (2010) as atividades que envolvem a emoção e a criatividade, além de tornar a aprendizagem mais prazerosa, auxiliam aos alunos na construção do conhecimento e na apropriação das informações introduzidas por essas aulas expositivas. A revista é uma forma de cativar os educandos e desenvolver o interesse deles pelo assunto.

Cabrera e Salvi (2006) afirmam que a promoção de um ambiente agradável, descontraído e afetivo favorece a autoestima dos alunos, a interação, a participação, o incentivo e o dinamismo auxiliando-os a aprender. 
Quando perguntados se gostaram da revista de forma geral, $87 \%$ dos alunos respondem sim totalmente para a pergunta (figura 7), 9\% não gostaram e $8 \%$ não gostaram parcialmente. Verificamos com isso que houve uma aceitação praticamente total da revista, os alunos realmente gostaram do material apresentado e aprovaram-no como recurso metodológico que pode ser utilizado em aulas de biologia.

Figura 7 - Gráfico representando as respostas da pergunta 5: Gostou da revista?

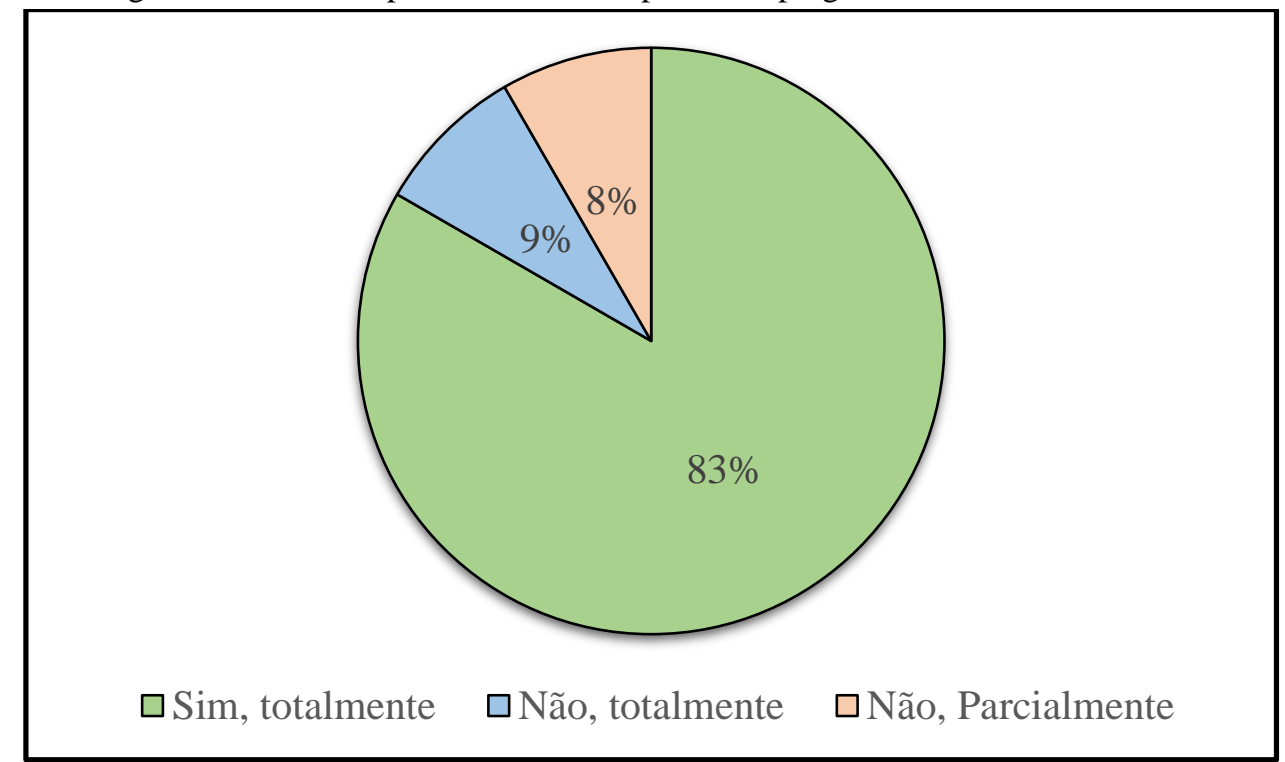

Fonte: Produzido pelos autores (2020).

Oliveira (2016) corrobora nesse ponto quando afirma que, as histórias em quadrinho apresentam materiais ricos para trabalhar os conteúdos transversais, pois tem boa aceitação entre alunos e pode render outras produções do conhecimento mais interessantes a cada faixa etária.

\subsection{ENTREVISTA COM A PROFESSORA SUPERVISORA}

Além do questionário aplicado com os alunos, buscamos verificar a aceitação também da professora de biologia responsável pela turma na qual a metodologia foi aplicada. No primeiro momento da entrevista, a professora foi questionada sobre qual recurso é normalmente utilizado para expor o conteúdo de alimentos transgênicos para os alunos. Na fala da professora ela:

normalmente utilizo livros, artigos científicos e vídeos para uma melhor compreensão do conteúdo abordado (professora entrevistada).

O professor é um dos principais responsáveis pelo ensino, pesquisa e gerenciamento do processo educacional. É ele quem escolhe os métodos utilizados para captar a atenção do seu público em um determinado período. $\mathrm{O}$ professor deve utilizar instrumentos didáticos que 
priorizem a participação do aluno, gerenciando suas expectativas e habilidades (PRIKLADNICKI et al., 2009).

A professora foi indagada se utilizaria a revista em quadrinhos em suas aulas, a mesma respondeu que:

sim totalmente, pois é algo totalmente diferenciado, prende e chama a atenção deles, a criação de um material desse com diálogos e cenas cotidianas e muito bem resumido e explicado ajuda muito na assimilação do conteúdo (professora entrevistada).

De acordo com Gomes e De Moraes Filho (2015) é relevante despertar o interesse e a curiosidade dos alunos durante as aulas e, cabe ao professor, estimular o aprendizado do estudante com estratégias de ensino que apresentem novidade, que prendam a atenção do mesmo pelo conteúdo que está sendo proposto para que haja a compreensão do tema abordado.

Foi perguntado ainda a professora se a revista facilitou o aprendizado de seus alunos, obteve-se a resposta de que:

sim totalmente, por ser um material com ilustrações e linguagem bem simples e
divertida, facilitou a assimilação do conteúdo e proporcionou que os alunos
conseguissem entender conceitos básicos e aplicações da Biotecnologia e as
diferenças ente organismos geneticamente modificados e transgênicos (professora
entrevistada).

Segundo Rota e Izquierdo (2003) uso de quadrinhos, além de possibilitar situações do cotidiano do estudante em processo de ensino e aprendizagem, permite a reflexão sobre diferentes temáticas, confronto de ideias, busca de soluções e alternativas para um problema apresentado.

Perguntamos ainda para a docente se a revista apresentava objetividade e clareza por meio da proposta estabelecida, a mesma respondeu que

sim totalmente, a revista apresenta o conteúdo de alimentos Transgênicos de forma bem resumida, objetiva, com total clareza do assunto, o aluno sem dúvida alguma entenderam os conceitos e curiosidades sobre o assunto (professora entrevistada).

De acordo com Pessan (2015) é de suma importância que haja uma abordagem do tema em uma visão mais ampla, ou seja, além de apresentar abordagem tradicional de como se dá o processo de transgenia, abordar também, as consequências nos mais diversos âmbitos, como: saúde, impactos ambientais, alimentação, desenvolvimento científico, entre outros.

Por último perguntamos se a revista está adequada a temática de alimentos Transgênicos, obtendo como resposta:

sim totalmente, não foge em nenhum momento do assunto é bem especifica e clara sobre o assunto, traz curiosidades, informa os malefícios e benefícios dos alimentos transgênicos, mostra alguns alimentos transgênicos e de que forma podemos identificá-los (professora entrevistada). 
Desta forma, consideramos ser de extrema relevância investigar o conhecimento a respeito dos conceitos relacionados a biotecnologia, que são fundamentais para a compreensão de elementos mais complexos, pois agregarão embasamento teórico e entendimento do assunto, além do simples significado das nomenclaturas, mas de uma forma que correlacione com o seu cotidiano e sejam capazes de propor soluções para circunstâncias que envolvam a genética (LA LUNA, 2011).

\section{CONSIDERAÇÕES FINAIS}

Consideramos os resultados obtidos bastante satisfatórios, houve uma receptividade bastante positiva com relação ao recurso metodológico utilizado, tanto por parte dos alunos quanto por parte da professora de biologia da turma utilizada para aplicação. É notável que a utilização de uma metodologia diferenciada foi muito bem visto por todos os envolvidos, sendo que o mesmo tirou a tensão de ambos e dinamizou o ambiente.

A produção e elaboração de uma revista em quadrinhos pode parecer um trabalho árduo e bastante complicado, no entanto, quando escrevemos e/ou criamos algo sobre um tema de interesse e com finalidades que objetivam a melhoria no ensino e aprendizagem dos nossos alunos este trabalho se torna leve e prazeroso. Com a revista foi possível contribuir com a formação de opiniões e conhecimento dos alunos, além de poder tirar dúvidas de um assunto de suma importância nos dias atuais.

Experiências como esta deveriam ser repetidas com mais frequência, tanto por professores titulares de turmas como por discentes do curso de biologia, podendo produzir materiais de diversos assuntos da área de ciências biológicas e desta forma aumentar a diversidade de recursos metodológicos utilizados no ensino de ciências e biologia.

Concordamos que este não é um trabalho finalizado, outros temas podem ser explorados e expostos em forma de quadrinhos, visto que a receptividade da turma foi bastante alta. Acreditamos também que a metodologia de produção precisa passar por aperfeiçoamento, outros programas de computação podem ser utilizados, novos formatos e modelos de apresentações podem ser testados e executados, para que assim possam chamar cada vez mais a atenção dos alunos.

\section{REFERÊNCIAS}

ALMEIDA, Paulo Nunes de. Educação lúdica: Técnicas e Jogos Pedagógicos. $2^{\text {a }}$. ed. São Paulo: Loyola, 2003. 
ALMEIDA, Caroline Medeiros Martins de; PROCHNOW, Tania Renata; LOPES, Paulo Tadeu Campos. O uso do lúdico no ensino de ciências: jogo didático sobre a química atmosférica. Universidad Distrital Francisco José de Caldas. Revista Góndola: Enseñanza y aprendizaje de las ciências. Barcelona, Vol. 11, nº 2, 2016. Disponível em: https://www.brazilianjournals.com/index.php/BRJD/article/view/1071/926. Acesso: 24 fev. 2021.

ALVES, Gilcean Silva. A biotecnologia dos transgênicos: Precaução é a palavra de ordem. Holos, Rio Grande do Norte, v. 2, p. 1-10. 2004. Disponível em: https://doi.org/10.15628/holos.2004.33. Acesso em: 12 set. 2020.

BRASIL. Portaria $\mathrm{n}^{\circ} 114$ de 6 de agosto de 2020. Estabelece regras das atividades dos Projetos Institucionais do Programa de Residência Pedagógica e do Programa de Bolsas de Iniciação à Docência (Pibid), 2020. Disponível em: http://cad.capes.gov.br/atoadministrativo-detalhar?idAtoAdmElastic=4682. Acesso em: 24 fev. 2021.

CABRERA, Waldirléia Baragatti; SALVI, Rosana F. A ludicidade para o ensino médio na disciplina de biologia: Contribuições ao processo de aprendizagem em conformidade com os pressupostos teóricos da Aprendizagem Significativa. 2006. 158 f. Paraná: Tese (Doutorado em Ensino de Ciências e Educação Matemática) - Universidade Estadual de Londrina, Paraná, 2006. Disponível em: https://www.sapili.org/livros/pt/cp025038.pdf. Acesso em: 20 set. 2020.

CARDOSO, Tiago Miguel Garcia; CAVALCANTE, Eduardo Luiz Dias; SOARES, Márlon Herbert Flora Barbosa. Atividades Lúdicas com Vídeos Digitais Amadores: Possibilidades para o Ensino de Química. In: ENCONTRO NACIONAL DE ENSINO DE QUÍMICA E ENCONTRO DE EDUCAÇÃO QUÍMICA DA BAHIA, 15. e 10., 2017, Salvador. Anais. Salvador: UFBA, 2017. Disponível em: http://www.eneq2012.qui.ufba.br/modulos/submissao/Upload/42765.pdf. Acesso em: 24 fev. 2021.

CIRNE, Moacy. Quadrinhos, sedução e paixão. 1ª. ed. Rio de Janeiro: Editora Vozes, 2000.

FREIRE, Paulo. Pedagogía de la autonomía: saberes necesarios para la práctica educativa. 45․ ed. México: Siglo XXI, 1997.

GOMES, Lázara Welyane Martins; DE MORAES FILHO, Aroldo Vieira. Alimentos transgênicos: utilização de metodologia alternativa para otimização do processo de ensino aprendizagem. Renefara, Goiânia, v. 7, n. 7, p. 325-336, 2015. Disponível em: https://www.fara.edu.br/sipe/index.php/renefara/article/view/342. Acesso em: 15 out. 2020.

LA LUNA, Alexandre. A importância do ensino de genética para o mundo atual. 2011. 44 f. Paraná: Trabalho de Conclusão de Curso (Especialização em Genética) - Universidade Federal do Paraná. Departamento de Genética. Votorantim. 2011. Disponível em: https://acervodigital.ufpr.br/handle/1884/32800 Acesso: 15 out. 2020.

LINSINGEN, Luana Von. Mangás e sua utilização pedagógica no Ensino de Ciências sob a perspectiva CTS. Ciência \& Ensino, São Paulo, v. 1, p. 1-9, 2007. Disponível em: http://143.0.234.106:3537/ojs/index.php/cienciaeensino/article/view/125/110. Acesso em: 10 set. 2020. 
MARTINS, Elisângela Karine. Histórias em quadrinhos no ensino de ciências: uma experiência para o ensino do sistema nervoso. 2012. 66 f. Paraná: Dissertação de Mestrado (Programa de Pós-Graduação em Ensino de Ciências e Tecnologia) - Universidade Tecnológica Federal do Paraná, Paraná, 2012. Disponível em: http://repositorio.utfpr.edu.br/jspui/handle/1/1256. Acesso em: 10 set. 2020.

MENDONÇA, David Soares Noronha. Prática Pedagógica em Educação Ambiental: Cartilha "Aventura da Vida nas Cavernas". 2010. 34 f. Belo Horizonte: Trabalho de Conclusão de Curso (Curso de Ciências Biológicas) - Centro Universitário Metodista Izabel Hendrix, Belo Horizonte, 2010. Disponível em: https://www.metodista.br/revistas/revistasizabela/index.php/aic/article/view/550/457. Acesso em: 12 set. 2020.

OLIVEIRA, Cláudia Vizoni Mattos Pedroso de. O uso de história em quadrinho digital (HQD) como ferramenta metodológica na disciplina de química. $2016.54 \mathrm{f}$. Florianópolis: Trabalho de Conclusão de Curso de Especialização (Programa de pósgraduação Educação na Cultura Digital) - Universidade Federal de Santa Catarina, Florianópolis, 2016. Disponível em: https://repositorio.ufsc.br/xmlui/handle/123456789/168986. Acesso em: 05 set. 2020.

PEDRANCINI, Vanessa Daiana et al. Saber Científico e Conhecimento Espontâneo: opiniões de alunos do ensino médio sobre transgênicos. Ciência \& Educação, Bauru, v. 14, n. 1, p. 135-146, 2008. Disponível em: https://www.scielo.br/scielo.php?pid=S151673132008000100009\&script=sci_abstract\&tlng=pt. Acesso em: 10 set. 2020.

PESSAN, Anderson da Silva. Transgênicos: explorando a controvérsia em aulas de ciências. 2015. 46 f. Vitória: Trabalho de conclusão de curso (Departamento de Teorias e Práticas Educacionais) - Universidade Federal do Espírito Santo, Vitória, 2015. Disponível em: https://labec.ufes.br/sites/labec.ufes.br/files/field/anexo/tcc final.pdf. Acesso em: 15 set. 2020 .

PRIKLADNICKI, Rafael et al. Ensino de engenharia de software: desafios, estratégias de ensino e lições aprendidas. In: FEES-Fórum de Educação em Engenharia de Software, 2009, Rio de Janeiro. Repositório de publicações do Fórum. Rio de Janeiro: PUC, 2009. p. 1-8, Disponível em:

https://www.researchgate.net/publication/228451551_Ensino_de_Engenharia_de_Software_D esafios_Estrategias_de_Ensino_e_Licoes_Aprendidas. Acesso em: 14 set. 2020.

RIBEIRO, Isabelle Geoffroy; MARIN, Victor Augustus. A falta de informação sobre os Organismos Geneticamente Modificados no Brasil. Ciência \& Saúde Coletiva, Rio de Janeiro, v. 17, p. 359-368, 2012. Disponível em: https://www.scielo.br/scielo.php?pid=S141381232012000200010\&script=sci_abstract\&tlng=pt. Acesso em: 15 set. 2020.

ROTA, Gladis; IZQUIERDO, Juan. Comics as a tool for teaching biotechnology in primary schools. Electronic Journal of Biotechnology, Chile, v. 6. n. 2. p.85-89. 2003. Disponível em: https://tspace.library.utoronto.ca/retrieve/2632/ej03012.pdf. Acesso em: 13 set. 2020.

SILVA, João Nelson. HQ nos Livros Didáticos. In: LUYTEN, Sonia. M. Bibe. História em Quadrinhos: Leitura Crítica. São Paulo: Paulinas, 1985. p. 79-85. 